\title{
Wyznaczenie stałych współczynników w ogólnym równaniu filtracji grawitacyjnej dla zawiesin węglowych
}

\begin{abstract}
Wprowadzenie
Procesy filtracyjne należą do głównych i zasadniczych procesów mechanicznego odwadniania zawiesin w ramach tzw. obiegów wodno-mułowych, stosowanych w zakładach przemysłowych, zarówno w zakładach przeróbki mechanicznej węgla i innych kopalin oraz w innych zakładach przemysłowych (Anielak 2000; Dahlstrom 1954; Ostrowska i in. 2013; Piecuch 2010).

Procesy filtracyjne można ogólnie usystematyzować w odniesieniu przede wszystkim do zakładów przeróbki mechanicznej kopalin na filtrację grawitacyjną, filtrację próżniową, ciśnieniową oraz filtrację odśrodkową (Piecuch 2010). Należy nadmienić, że procesowi filtracji, który jest ogólnie zdefiniowany jako proces napływu na przegrodę porowatą mieszaniny cieczy i ciała stałego - w którym to ciecz przechodzi przez przegrodę porowatą jako filtrat, oraz w którym części stałe nadawy zatrzymywane są na przegrodzie porowatej tworząc tzw. osad, bądź też częściowo zatrzymywane są wewnątrz przegrody porowatej,

* Prof. dr hab. inż., Wydział Inżynierii Lądowej, Środowiska i Geodezji, Politechnika Koszalińska, Koszalin; e-mail: tadeusz.piecuch@tu.koszalin.pl

** Mgr inż., Wydział Inżynierii Lądowej, Środowiska i Geodezji, Politechnika Koszalińska, Koszalin; e-mail: czapiewski-pawel@wp.pl

*** Dr hab. inż., prof. PK, Wydział Inżynierii Lądowej, Środowiska i Geodezji, Politechnika Koszalińska, Koszalin; e-mail: jacek@wilsig.tu.koszalin.pl
\end{abstract}


wypełniając pory (kolmatacja) (Kliber i Wiśniewski 2009; Piecuch 2009, 2010) - procesowi temu towarzyszy równolegle proces sorpcji (Anielak 2000; Gumińska 2003; Ostrowska i in. 2013; Hewelke i in. 2014; Piekarski 2011; Tomaszewska 2011).

Oddzielną problematyką, którą także można ująć w ramach określonej systematyki procesów filtracyjnych jest filtracja membranowa (mikrofiltracja, ultrafiltracja) (Kabsch-Korbutowicz, Urbanowska 2009; Kliber, Wiśniewski 2009), która ze względu na specyfikę nie została ujęta w powyższej ogólnej systematyce filtracji (Piecuch 2009, 2010), zorientowanej na ich stosowaniu w zakładach przeróbki surowców mineralnych.

Odnosząc się do procesów filtracji stosowanych w zakładach przeróbki mechanicznej kopalin należy zaznaczyć, że najczęściej stosowane są procesy filtracji próżniowej i ciśnieniowej. Natomiast rzadziej stosowana jest filtracja odśrodkowa dla zawiesin bardzo drobnoziarnistych ze względu na zatykanie się koszy wirówek filtracyjnych; chyba, że dotyczy to zawiesin gruboziarnistych, a więc miałowych (po osadzarkach) odwadnianych w wirówkach typu NAEL. Niemniej jednak należy zwrócić uwagę, że stosowane procesy filtracji próżniowej lub ciśnieniowej w zakładach przeróbki mechanicznej surowców mineralnych (Piecuch 2010) nie są łatwe do prowadzenia, gdyż istnieją określone uwarunkowania ich stosowania (Dahlstrom 1954). Są to procesy kosztowne zarówno eksploatacyjnie, jak i inwestycyjnie (amortyzacja wchodzi w skład kosztów eksploatacyjnych).

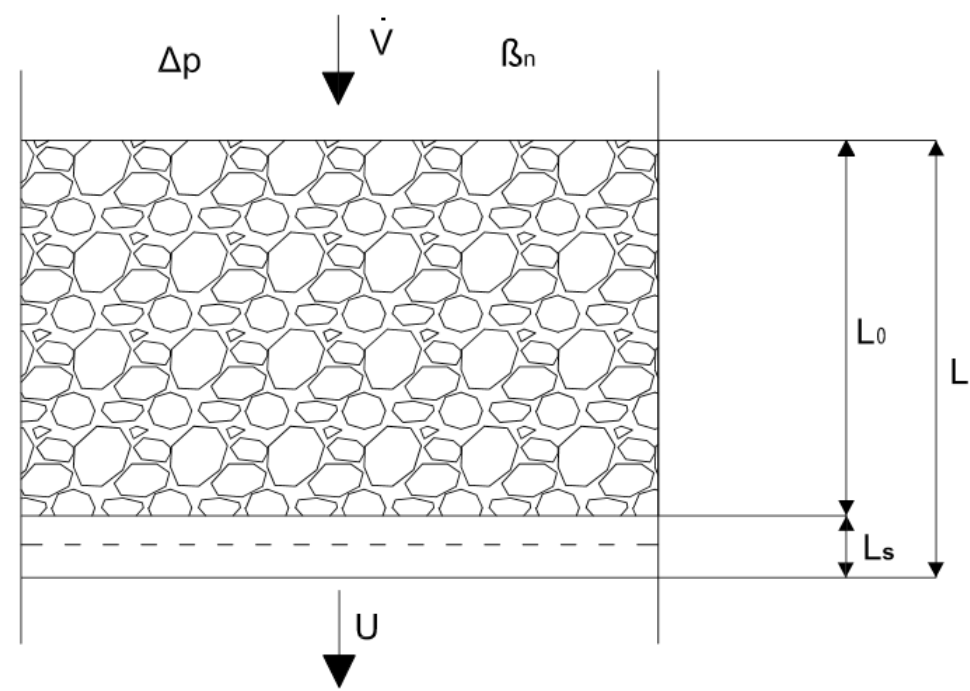

Rys. 1. Schemat przepływu płynów przez warstwę porowatą podczas procesu filtracji $U$ - prędkość filtracji, $L$ - grubość przegrody porowatej, $L o$ - grubość osadu, $L_{S-}$ grubość siatki filtracyjnej, $\Delta p$ - ciśnienie filtracji, $\dot{V}$ - wydajność objętościowa, $\beta n$ - zagęszczenie nadawy (Piecuch 2010)

Fig. 1. Scheme of the fluid flow through porous layer during the filtration $U$ - filtration velocity, $L$ - the thickness of the porous septum, $L_{O}$ - the thickness of the solid, $L_{S}-$ the thickness of the filter, $\Delta p$ - pressure filtration, $\dot{V}-$ volumetric efficiency, $\beta n-$ density given to a mixture (Piecuch 2010) 
Dlatego nie można zupełnie wykluczyć pewnej dosyć śmiałej, aczkolwiek również dyskusyjnej metody odwadniania zawiesin poprodukcyjnych w ramach procesu filtracji grawitacyjnej (rys. 1) i właśnie do tego zmierzają obecne badania o charakterze podstawowym, które przedstawiono w niniejszej publikacji. Publikacja ta jest pierwszym etapem badań zmierzającym w tym kierunku.

Zatem, w publikacji przedstawiono proces grawitacyjnego odwadniania zawiesin na siatce filtracyjnej (rys. 1), o grubości $L_{S}$, która może być rozciągnięta i umocowana w odpowiednich ramach (obudowie), na której tworzy się osad o grubości $L_{O}$, a taka filtracja jest możliwa dla zawiesin poprodukcyjnych o możliwie relatywnie małym zagęszczeniu w stosunku do wymagań filtracji próżniowej lub ciśnieniowej, gdzie wymagane jest zagęszczenie kilkuset $\mathrm{g} / \mathrm{dm}^{3}$ (Piecuch 2010).

Kolejnym etapem badań omówionych $\mathrm{w}$ niniejszej publikacji będzie następna praca, dotycząca filtracji grawitacyjnej, w której na siatce filtracyjnej będzie ułożone złoże filtracyjne $\mathrm{z}$ tego samego materiału co zawiesina wprowadzona do złoża - przykładowo złoża węglowego drobnoziarnistego, które ma zatrzymać częściowo doprowadzoną zawiesinę, w postaci osadu, a częściowo zatrzymać zawiesinę w wyniku kolmatacji złoża.

\section{Badania własne}

\subsection{Opis stanowiska badań}

Badania rozpoczęto od przygotowania węgla kamiennego do badań. W tym celu rozdrobniono węgiel w kruszarce laboratoryjnej. Następnie otrzymany węgiel poddany był

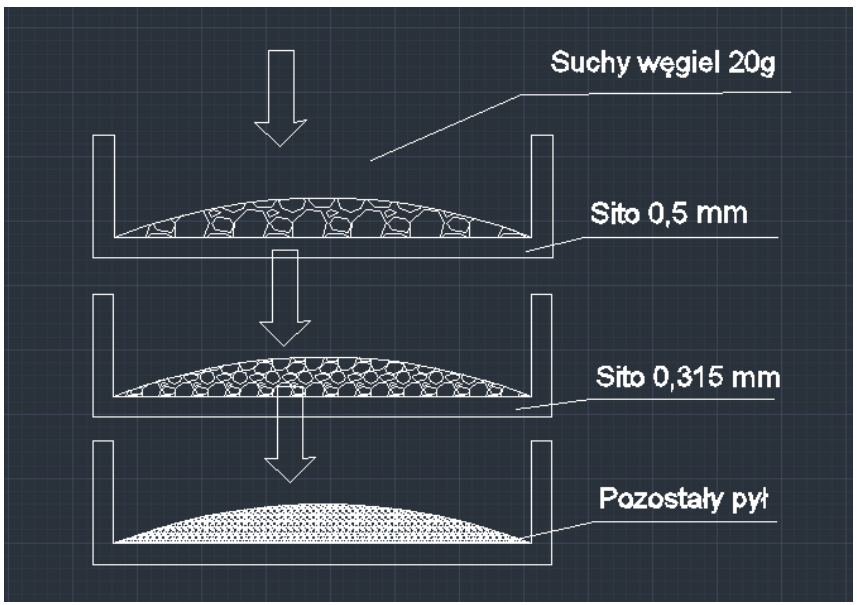

Rys. 2. Schemat procesu przesiewania

Fig. 2. Scheme of the process of sieving 
procesowi przesiewania (rys. 2). Do tego celu użyto przesiewacza firmy mLw; otrzymano klasę ziarnową węgla o wielkości ziaren $0,5-0,315 \mathrm{~mm}$.

Kolejnym etapem przygotowań było zbudowanie stanowiska badawczego, w którego skład wchodzą: plastikowa rura o wysokości $200 \mathrm{~cm}$ oraz metalowy mechanizm zamykający wylot wody (rys. 3). Mechanizm ten zbudowany jest z metalowej obejmy, w której umieszczona jest siatka filtracyjna o rozmiarze oczek $0,20 \mathrm{~mm}$. Całość izolowana jest uszczelkami uniemożliwiającymi niekontrolowany wylot nadawy. Na końcu obejmy znajduje się mechanizm zamykający wylot.

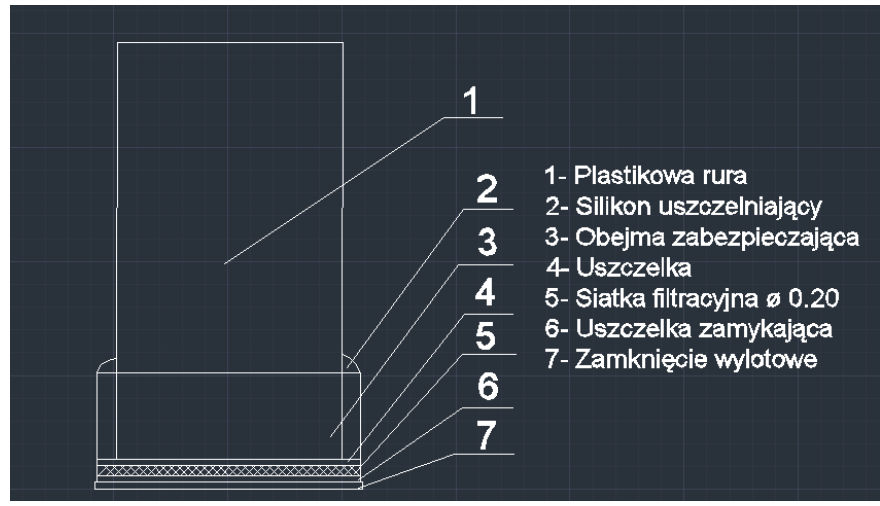

Rys. 3. Schemat elementu pomiarowego

Fig. 3. Scheme of the measuring element

\subsection{Przebieg badań}

Najpierw zamontowano plastikową rurę ze specjalnie wykonanym mechanizmem zamykającym, uniemożliwiającym natychmiastowy wylot nadawy. Następnie zważono węgiel, który użyto do badań w następujących dawkach: $10 \mathrm{~g} / \mathrm{dm}^{3}, 20 \mathrm{~g} / \mathrm{dm}^{3}, 40 \mathrm{~g} / \mathrm{dm}^{3}$ oraz $60 \mathrm{~g} / \mathrm{dm}^{3}$. Objętość przygotowanej nadawy jaka była użyta do badania wynosiła odpowiednio: $1 \mathrm{dm}^{3}, 1,5 \mathrm{dm}^{3}$ oraz $2 \mathrm{dm}^{3}$.

Badania przeprowadzono w taki sposób, aby wyznaczyć wartość $t$ ', która określana jest w literaturze jako stała siatki (Piecuch 2008, 2009; Piekarski 2011). Parametr ten jest potrzebny, aby obliczyć opór siatki $R s$. W tym celu do plastikowej rury wlano najpierw odpowiednio $1 \mathrm{dm}^{3}, 1,5 \mathrm{dm}^{3}$ oraz $2 \mathrm{dm}^{3}$ wody i odczytano poszczególne czasy jej przepływu przez siatkę filtracyjną.

Następnie, osobno dla każdej objętości mieszaniny $\left(1 \mathrm{dm}^{3}, 1,5 \mathrm{dm}^{3}\right.$ oraz $\left.2 \mathrm{dm}^{3}\right)$ przygotowano następujące dawki węgla: $10 \mathrm{~g} / \mathrm{dm}^{3}, 20 \mathrm{~g} / \mathrm{dm}^{3}, 40 \mathrm{~g} / \mathrm{dm}^{3}$ oraz $60 \mathrm{~g} / \mathrm{dm}^{3}$ zwane dalej zagęszczeniem nadawy. Całość była wymieszana i natychmiast wprowadzona do plastiko- 
wej rury. Odczytano czas ubytku nadawy dla $1 \mathrm{dm}^{3}$ cieczy o 0,$25 ; 0,50 ; 0,75$ i $1,00 \mathrm{dm}^{3}$, dla $1,5 \mathrm{dm}^{3}$ cieczy o 0,$25 ; 0,50 ; 0,75 ; 1,00 ; 1,25$ i $1,50 \mathrm{dm}^{3}$ oraz dla $2 \mathrm{dm}^{3}$ cieczy o: 0,$25 ; 0,50$; 0,$75 ; 1,00 ; 1,25 ; 1,50 ; 1,75$ i $2,00 \mathrm{dm}^{3}$. Wyniki pomiarów zostały sporządzone w formie trzynastu tabel oraz siedmiu wykresów.

\section{Wyniki badań i ich analiza}

\subsection{Wykorzystane wzory i przeksztalcenia}

Podstawowym wzorem użytym w celu wyznaczenia stałych współczynników w filtracji grawitacyjnej, było równanie filtracji według Piecucha, które ma postać (Piecuch 2009) :

$$
\dot{V}=\frac{\Delta p}{t^{\prime} \frac{\mu}{A}+\frac{\mu}{b} \frac{\left(1-\varepsilon_{1}\right)^{2}}{\varepsilon_{1}^{3} k} \frac{L_{1}}{A}+\frac{\mu}{b} \frac{V \beta_{n}}{A^{2}\left(1-\varepsilon_{2}\right) \delta_{s}}}
$$

Powyższy wzór można zapisać również w wersji uproszczonej:

$$
\dot{V}=\frac{\Delta p}{R_{s}+R_{z l}+R_{o s}}
$$

W podanej uproszczonej wersji wzoru (2), sumę w mianowniku można tłumaczyć jako: opór siatki $R_{s}+$ opór złoża $R_{z l}+$ opór osadu na złożu $R_{o s}$. W niniejszych rozważaniach $R_{Z}$ pomijamy, bowiem prowadzimy filtrację bezpośrednio na siatce filtracyjnej.

Następnie z ogólnego równania przepływu płynu przez siatkę filtracyjną (Piecuch 2009; Ostrowska i in. 2013):

$$
\dot{V}=\frac{\Delta p}{t^{\prime} \cdot \frac{\mu}{A}}
$$

wyliczamy stałą siatki $t^{\prime}$ :

$$
t^{\prime}=\frac{\Delta p}{\frac{\mu}{A} \cdot \dot{V}}
$$

Parametry po prawej stronie równania są mierzalne w trakcie doświadczenia.

Kolejnym wykorzystanym równaniem był wzór na opór siatki filtracyjnej $R_{s}$, który ma postać (Piecuch 2009, 2010): 


$$
R_{S}=t^{\prime} \cdot \frac{\mu}{A}
$$

Aby uzyskać wzór na stałą filtracji grawitacyjnej $b$ w równaniu Piecucha (2009) przekształcono poniższy ogólny zapis równania według Piecucha (Piecuch 2009):

$$
\dot{V}=\frac{\Delta p}{t^{\prime} \cdot \frac{\mu}{A}+\frac{\mu}{b} \cdot \frac{V \cdot \beta_{N}}{A^{2} \cdot(1-\varepsilon) \cdot \delta_{s}}}
$$

otrzymując wzór na szukaną stałą $b$ :

$$
b=\frac{\mu \cdot V \cdot \beta_{n} \cdot \dot{V}}{A^{2}(1-\varepsilon) \cdot \delta_{s} \cdot \Delta p-\dot{V} \cdot t^{\prime} \cdot \mu \cdot A \cdot(1-\varepsilon) \cdot \delta_{s}}
$$

\subsection{Przykładowe obliczenie}

W celu obliczenia stałej siatki filtracyjnej $t^{\prime}$ dla $1 \mathrm{dm}^{3}$ skorzystano ze wzoru (4):

$$
t^{\prime}=\frac{102050 \frac{\mathrm{N}}{\mathrm{m}^{2}}}{\frac{0,001 \frac{\mathrm{N} \cdot \mathrm{s}}{\mathrm{m}^{2}}}{0,00246 \mathrm{~m}^{2}} \cdot 0,0011 \frac{\mathrm{m}^{3}}{\mathrm{~s}}}=228220909,1 \frac{1}{\mathrm{~m}}
$$

Obliczenie oporu siatki $R_{S}$ dla $1 \mathrm{dm}^{3}$ przeprowadzono według wzoru (5):

$$
R_{S}=t^{\prime} \cdot \frac{\mu}{A}=228220909,1 \frac{1}{m} \cdot \frac{0,001 \frac{\mathrm{N} \cdot s}{\mathrm{~m}^{2}}}{0,00246 \mathrm{~m}^{2}}=92772727,28 \frac{\mathrm{N} \cdot \mathrm{s}}{\mathrm{m}^{5}}
$$

Końcowym etapem obliczeń było wyznaczenie stałej filtracji oznaczanej symbolem $b$ dla $1 \mathrm{dm}^{3}$ zgodnie ze wzorem (7):

$$
\begin{gathered}
b=\frac{0,001 \cdot 0,001 \cdot 100 \cdot 0,00005}{0,00246^{2} \cdot 0,995 \cdot 0,95 \cdot 102050-0,00005 \cdot 228220909,1 \cdot 0,001 \cdot 0,00246 \cdot 0,995 \cdot 0,95}= \\
=8,97 \cdot 10^{-9}
\end{gathered}
$$


Zapis stałej filtracji oznaczonej symbolem $b$ w postaci wymiarów fizykalnych:

$$
b=\frac{\frac{N \cdot s}{m^{2}} \cdot m^{3} \cdot \frac{N}{m^{3}} \cdot \frac{m^{3}}{s}}{m^{2} \cdot 1 \cdot \frac{N}{m^{3}} \cdot \frac{N}{m^{2}}-\frac{m^{3}}{s} \cdot \frac{1}{m} \cdot \frac{N \cdot s}{m^{2}} \cdot m^{2} \cdot 1 \cdot \frac{N}{m^{3}}}
$$

\subsection{Zestawienie tabelaryczne oraz graficzne otrzymanych wyników}

Tabela 1. Zestawienie wyników średniego ciśnienia $\Delta p_{\text {sr }}$

Table 1. Summary of results of medium pressure $\Delta p s i r$

\begin{tabular}{|c|c|c|}
\hline Lp. & Objętość nadawy $\left[\mathrm{dm}^{3}\right]$ & Wartość ciśnienia średniego $\Delta p_{\mathrm{sr}}\left[\mathrm{N} / \mathrm{m}^{2}\right]$ \\
\hline 1. & 1,0 & 2050 \\
\hline 2. & 1,5 & 3050 \\
\hline 3. & 2,0 & 4050 \\
\hline
\end{tabular}

Tabela 2. Zestawienie wyników ciśnienia $\Delta p$

Table 2. Summary results of pressure $\Delta p$

\begin{tabular}{|c|c|c|}
\hline Lp. & Objętość nadawy $\left[\mathrm{dm}^{3}\right]$ & Wartość ciśnienia $\Delta p\left[\mathrm{~N} / \mathrm{m}^{2}\right]$ \\
\hline 1. & 1 & 102050 \\
\hline 2. & 1,5 & 103050 \\
\hline 3. & 2 & 104050 \\
\hline
\end{tabular}

Tabela 3. Zestawienie wyników obliczeń stałej siatki filtracyjnej $t^{\prime}$

Table 3. Summary results of calculating the fixed filter mesh $t^{\prime}$

\begin{tabular}{|c|c|c|}
\hline Lp. & Objętość nadawy $\left[\mathrm{dm}^{3}\right]$ & Stałej filtracyjnej $t^{\prime}[1 / m]$ \\
\hline 1. & 1,0 & 228220909,1 \\
\hline 2. & 1,5 & 211252500,0 \\
\hline 3. & 2,0 & 182830714,3 \\
\hline
\end{tabular}


Tabela 4. Zestawienie wyników obliczeń oporu siatki $R_{s}$

Table 4. Summary results of the calculation of the net resistance $R_{s}$

\begin{tabular}{|c|c|c|}
\hline Lp. & Objętość nadawy $\left[\mathrm{dm}^{3}\right]$ & Opór siatki $R_{s}\left[\frac{N \cdot s}{m^{5}}\right]$ \\
\hline 1. & 1,0 & 92772727,28 \\
\hline 2. & 1,5 & 85875000,00 \\
\hline 3. & 2,0 & 74321428,57 \\
\hline
\end{tabular}

Tabela 5. Zestawienie wyników obliczeń stałej filtracji $b$ dla zagęszczenia $\beta=10,20,30,40 \mathrm{~g} / \mathrm{dm}^{3}$ przy objętości nadawy $1 \mathrm{dm}^{3}$

Table 5. Summary of the results of calculations constant filtration $b$ thicken $\beta=10,20,30,40 \mathrm{~g} / \mathrm{dm}^{3}$ by volume of the feed $1 \mathrm{dm}^{3}$

\begin{tabular}{|c|c|c|}
\hline Lp. & Zagęszczenie $\beta$ dla nadawy $1 \mathrm{dm}^{3}\left[\mathrm{~g} / \mathrm{dm}^{3}\right]$ & Stałej filtracji $b$ \\
\hline 1. & 10 & $8,97 \cdot 10^{-9}$ \\
\hline 2. & 20 & $1,11 \cdot 10^{-8}$ \\
\hline 3. & 30 & $1,24 \cdot 10^{-8}$ \\
\hline 4. & 40 & $1,35 \cdot 10^{-8}$ \\
\hline
\end{tabular}

Tabela 6. Zestawienie wyników obliczeń stałej filtracji $b$ dla zagęszczenia $\beta=10,20,30,40 \mathrm{~g} / \mathrm{dm}^{3}$ przy objętości nadawy $1,5 \mathrm{dm}^{3}$

Table 6. Results of calculations constant filtration $b$ thicken $\beta=10,20,30,40 \mathrm{~g} / \mathrm{dm}^{3}$ at a volume of $1.5 \mathrm{dm}^{3}$ feed

\begin{tabular}{|c|c|c|}
\hline Lp. & Zagęszczenie $\beta$ dla nadawy $1,5 \mathrm{dm}^{3}\left[\mathrm{~g} / \mathrm{dm}^{3}\right]$ & Stałej filtracji $b$ \\
\hline 1. & 10 & $1,33 \cdot 10^{-8}$ \\
\hline 2. & 20 & $1,81 \cdot 10^{-8}$ \\
\hline 3. & 30 & $2,08 \cdot 10^{-8}$ \\
\hline 4. & 40 & $2,25 \cdot 10^{-8}$ \\
\hline
\end{tabular}

Tabela 7. Zestawienie wyników obliczeń stałej filtracji $b$ dla zagęszczenia $\beta=10,20,30,40 \mathrm{~g} / \mathrm{dm}^{3}$ przy objętości nadawy $2 \mathrm{dm}^{3}$

Table 7. Summary results of calculations a constant filter $b$ to thicken $\beta=10,20,30,40 \mathrm{~g} / \mathrm{dm}^{3}$ with a volume of $2 \mathrm{dm}^{3}$ feed

\begin{tabular}{|c|c|c|}
\hline Lp. & Zagęszczenie $\beta$ dla nadawy $2 \mathrm{dm}^{3}\left[\mathrm{~g} / \mathrm{dm}^{3}\right]$ & Stałej filtracji $b$ \\
\hline 1. & 10 & $1,80 \cdot 10^{-8}$ \\
\hline 2. & 20 & $2,44 \cdot 10^{-8}$ \\
\hline 3. & 30 & $2,87 \cdot 10^{-8}$ \\
\hline 4. & 40 & $2,98 \cdot 10^{-8}$ \\
\hline
\end{tabular}


Na rysunku 4 przedstawiono zależność pomiędzy współczynnikiem filtracji grawitacyjnej $b$ oraz zagęszczeniem nadawy $\beta$, dla każdej z rozpatrywanych objętości nadawy, czyli odpowiedniego zmiennego w czasie naporu stanowiącego ciśnienie tej filtracji odniesionego do średniej wartości tegoż ciśnienia w czasie filtracji.

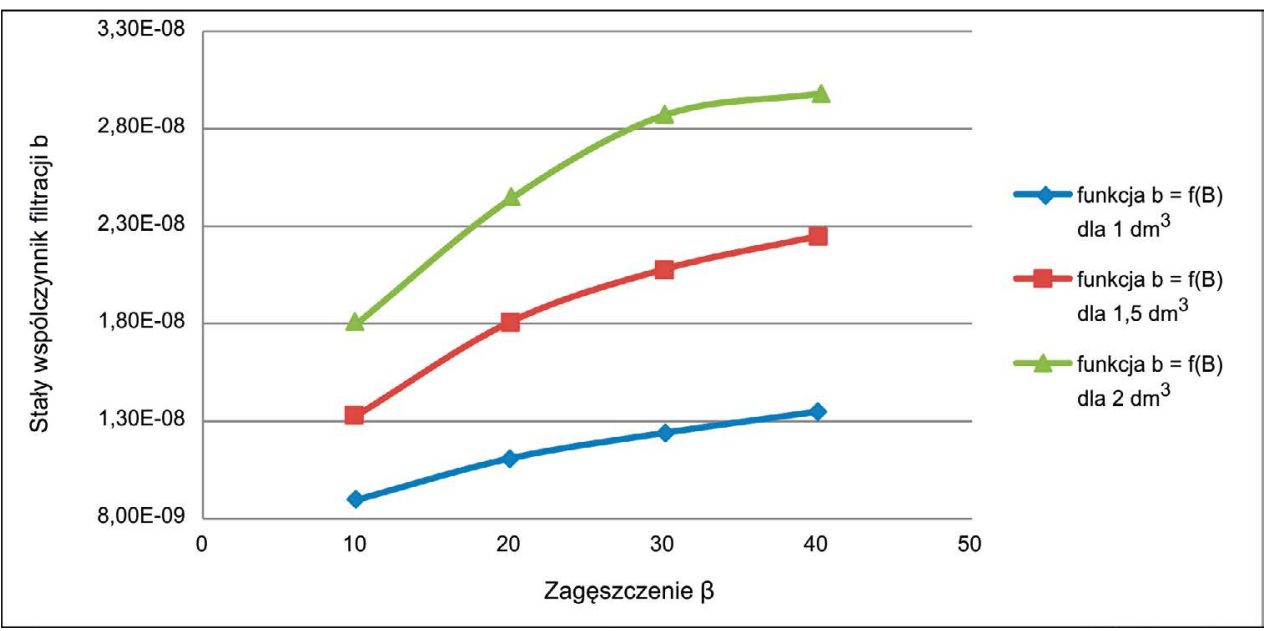

Rys. 4. Wykres zależności stałej filtracji $b$ od zagęszczenia $\beta$ dla objętości nadawyl $\mathrm{dm}^{3} ; 1,5 \mathrm{dm}^{3}$ oraz $2 \mathrm{dm}^{3}$

Fig. 4. A plot of the constant density of the filtration $b$ of $\beta$ for $1 \mathrm{dm}^{3} ; 1.5 \mathrm{dm}^{3}$ and $2 \mathrm{dm}^{3}$ volume of feed

Niżej przedstawione zostały wyniki w zależności od rozpatrywanej objętości nadawy; tabele 8-9 wraz z wykresami (rys. 5-6) przy objętości nadawy $1 \mathrm{dm}^{3}$

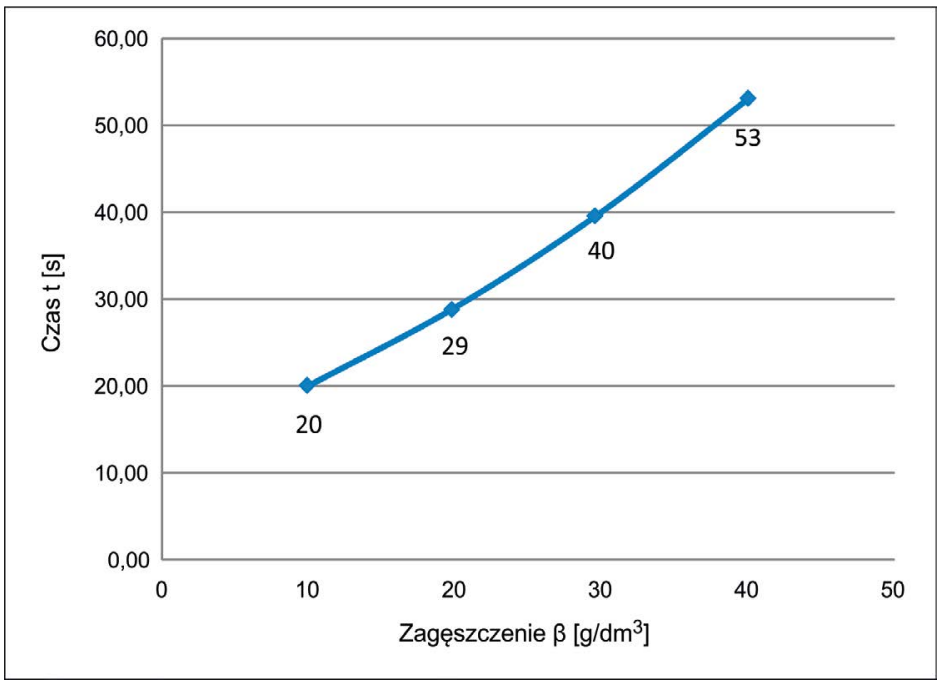

Rys. 5. Wpływ zagęszczenia nadawy $\beta$ na czas filtracji przy objętości $1 \mathrm{dm}^{3}$

Fig. 5. The effect of $\beta$ feed density at the time of filtration at a volume of $1 \mathrm{dm}^{3}$ 
Tabela 8. Zestawienie czasu filtracji dla poszczególnych zagęszczeń nadawy przy objętości $1 \mathrm{dm}^{3}$

Table 8. Summary of the filtration time for different densities feed at a volume of $1 \mathrm{dm}^{3}$

\begin{tabular}{|c|c|c|}
\hline Lp. & Czas $t[\mathrm{~s}]$ & Zagęszczenie $\beta\left[\mathrm{g} / \mathrm{dm}^{3}\right]$ \\
\hline 1. & 20 & 10 \\
\hline 2. & 29 & 20 \\
\hline 3. & 40 & 30 \\
\hline 4. & 62 & 40 \\
\hline
\end{tabular}

Poniżej (rys. 6, tab. 9) przedstawiono czas ubytku nadawy o 0,$25 ; 0,50 ; 0,75$ oraz o 1,00 przy poszczególnych jej zagęszczeniach w objętości $1 \mathrm{dm}^{3}$.

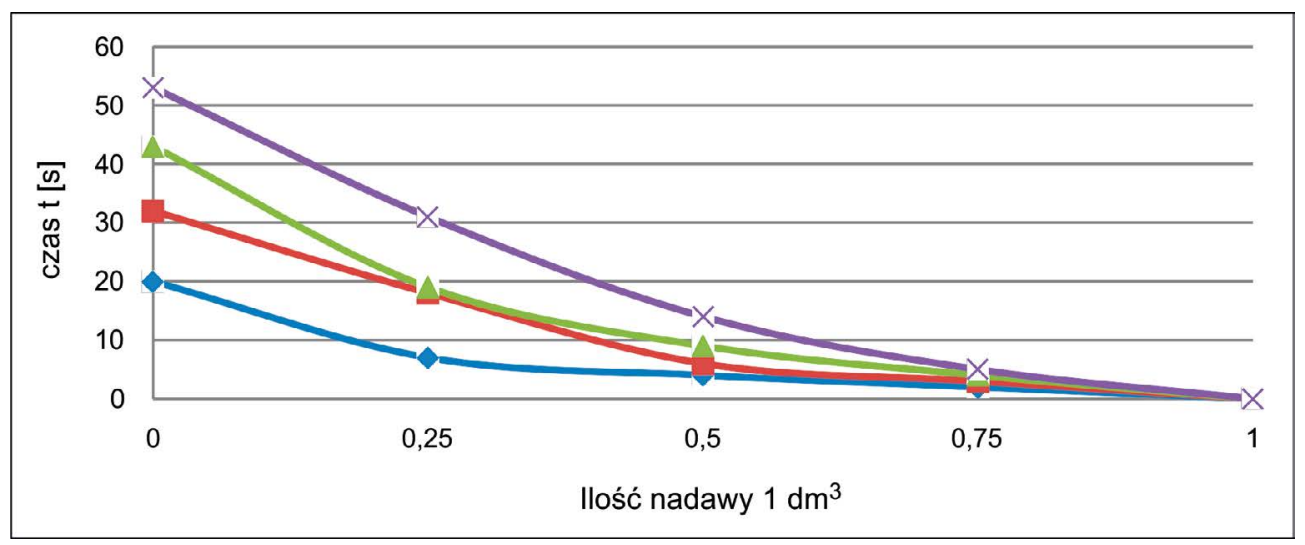

Rys. 6. Przepływ nadawy o zagęszczeniu $\beta=10,20,30,40 \mathrm{~g} / \mathrm{dm}^{3} \mathrm{dla} 1 \mathrm{dm}^{3}$

Fig. 6. The flow of feed concentration $\beta=10,20,30,40 \mathrm{~g} / \mathrm{dm}^{3}$ for $1.0 \mathrm{dm}^{3}$

Tabela 9. Zestawienie czasu przepływu nadawy dla zagęszczenia $\beta=10,20,30,40 \mathrm{~g} / \mathrm{dm}^{3} \mathrm{w} 1 \mathrm{dm}^{3}$

Table 9. Selection of the flow time of the feed for the density $\beta=10,20,30,40 \mathrm{~g} / \mathrm{dm}^{3}$ in $1 \mathrm{dm}^{3}$

\begin{tabular}{|c|c|c|c|c|c|}
\hline \multirow{2}{*}{ Lp. } & \multirow{2}{*}{$\begin{array}{c}\text { Ilość nadawy } \\
\text { ubytek } \\
{\left[\mathrm{dm}^{3}\right]}\end{array}$} & \multicolumn{4}{|c|}{ Czas $t[\mathrm{~s}]$} \\
\cline { 3 - 6 } & 1,00 & $10 \mathrm{~g} / \mathrm{dm}^{3}$ & $20 \mathrm{~g} / \mathrm{dm}^{3}$ & $30 \mathrm{~g} / \mathrm{dm}^{3}$ & $40 \mathrm{~g} / \mathrm{dm}^{3}$ \\
\hline 1. & 0,75 & 0 & 0 & 0 & 0 \\
\hline 2. & 0,50 & 2 & 3 & 4 & 5 \\
\hline 3. & 0,25 & 4 & 6 & 9 & 14 \\
\hline 4. & 0,00 & 20 & 32 & 43 & 31 \\
\hline 5. & & & & & 53 \\
\hline
\end{tabular}


Tabele 10 i 11 wraz z wykresami (rys. 7-8) przy objętości nadawy $1,5 \mathrm{dm}^{3}$.

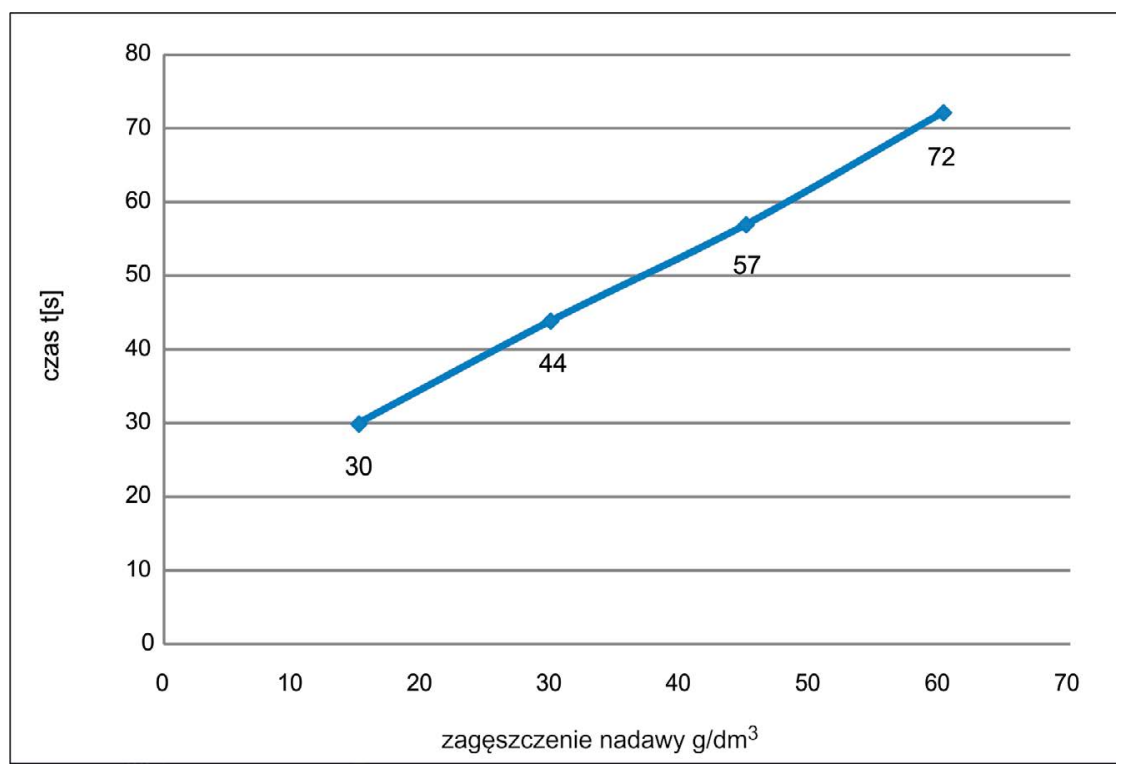

Rys. 7. Wpływ zagęszczenia nadawy na czas filtracji przy objętości $1,5 \mathrm{dm}^{3}$

Fig. 7. The influence of density feed on the filtration time at a volume of $1.5 \mathrm{dm}^{3}$

Tabela 10. Zestawienie czasu filtracji dla poszczególnych zagęszczeń nadawy przy objętości $1,5 \mathrm{dm}^{3}$

Table 10. Summary of the filtration time for different densities feed at a volume of $1.5 \mathrm{dm}^{3}$

\begin{tabular}{|c|c|c|}
\hline Lp. & Czas $\mathrm{t}[\mathrm{s}]$ & Zagęszczenie $\beta\left[\mathrm{g} / \mathrm{dm}^{3}\right]$ \\
\hline 1. & 30 & 10 \\
\hline 2. & 44 & 20 \\
\hline 3. & 57 & 30 \\
\hline 4. & 79 & 40 \\
\hline
\end{tabular}

Na rysunku 8 przedstawiono czas ubytku nadawy o 0,$25 ; 0,50 ; 0,75 ; 1,00 ; 1,25$ oraz $1,50 \mathrm{dm}^{3}$ przy poszczególnych jej zagęszczeniach i objętości $1,5 \mathrm{dm}^{3}$.

Tabele 12 i 13 wraz z wykresami (rys. 9-10) przy objętości nadawy $2 \mathrm{dm}^{3}$ przedstawiono poniżej.

$\mathrm{Na}$ rysunku $10 \mathrm{i}$ w tabeli 13 przedstawiono czas ubytku nadawy o 0,$25 ; 0,50$; 0,$75 ; 1,00 ; 1,25 ; 1,50 ; 1,75$ oraz o $2,00 \mathrm{dm}^{3}$ przy poszczególnych jej zagęszczeniach i objętości $2 \mathrm{dm}^{3}$. 


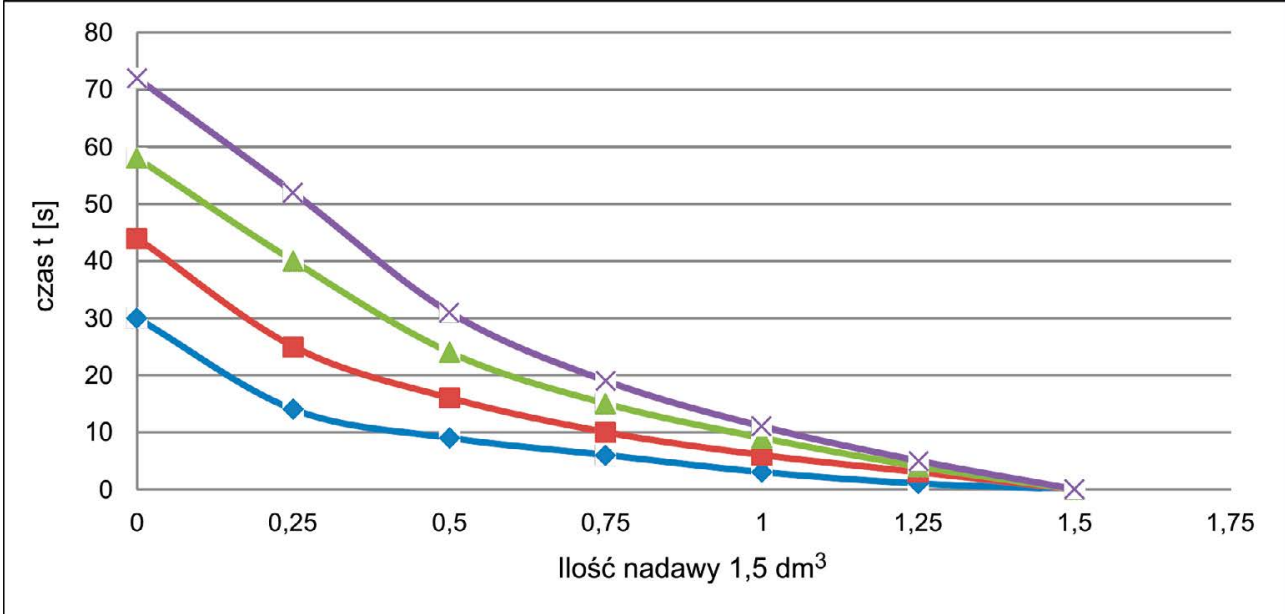

Rys. 8. Przepływ nadawy o zagęszczeniu $\beta=10,20,30,40 \mathrm{~g} / \mathrm{dm}^{3} \mathrm{dla} 1,5 \mathrm{dm}^{3}$

Fig. 8. The flow of feed concentration $\beta=10,20,30,40 \mathrm{~g} / \mathrm{dm}^{3}$ for $1.5 \mathrm{dm}^{3}$

Tabela 11. Zestawienie czasu przepływu nadawy dla zagęszczenia $\beta=10,20,30,40 \mathrm{~g} / \mathrm{dm}^{3} \mathrm{dla} 1,5 \mathrm{dm}^{3}$

Table 11. Selection of the flow time for the feed to thicken $\beta=10,20,30,40 \mathrm{~g} / \mathrm{dm}^{3}$ for $1.5 \mathrm{dm}^{3}$

\begin{tabular}{|c|c|c|c|c|c|}
\hline Lp. & Ilość nadawy $\left[\mathrm{dm}^{3}\right]$ & \multicolumn{4}{|c|}{ Czas $t[\mathrm{~s}]$} \\
\hline 1. & 1,50 & 0,00 & 0,00 & 0,00 & 0,00 \\
\hline 2. & 1,25 & 1 & 3 & 4 & 5 \\
\hline 3. & 1,00 & 3 & 6 & 9 & 11 \\
\hline 4. & 0,75 & 6 & 10 & 15 & 19 \\
\hline 5. & 0,50 & 9 & 16 & 24 & 31 \\
\hline 6. & 0,25 & 14 & 25 & 40 & 52 \\
\hline 7. & 0,00 & 30 & 44 & 58 & 72 \\
\hline
\end{tabular}

Tabela 12. Zestawienie czasu filtracji dla poszczególnych zagęszczeń nadawy przy objętości $2 \mathrm{dm}^{3}$

Table 12. Summary of the filtration time for different densities feed at a volume of $2 \mathrm{dm}^{3}$

\begin{tabular}{|c|c|c|}
\hline Lp. & Czas $t[\mathrm{~s}]$ & Zagęszczenie $\beta\left[\mathrm{g} / \mathrm{dm}^{3}\right]$ \\
\hline 1. & 39 & 10 \\
\hline 2. & 58 & 20 \\
\hline 3. & 75 & 30 \\
\hline 4. & 98 & 40 \\
\hline
\end{tabular}




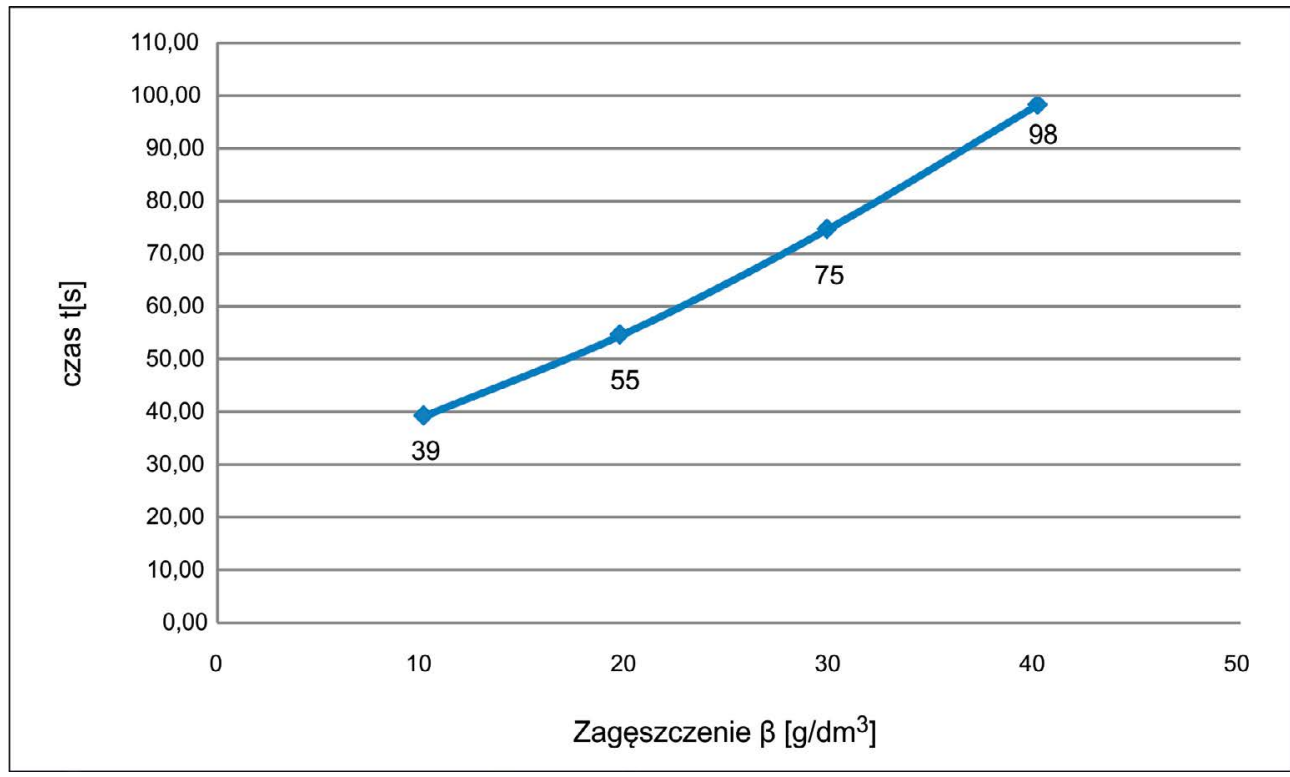

Rys. 9. Wpływ zagęszczenia nadawy na czas filtracji przy objętości $2 \mathrm{dm}^{3}$

Fig. 9. The influence of density feed on the filtration time at a volume of $2 \mathrm{dm}^{3}$

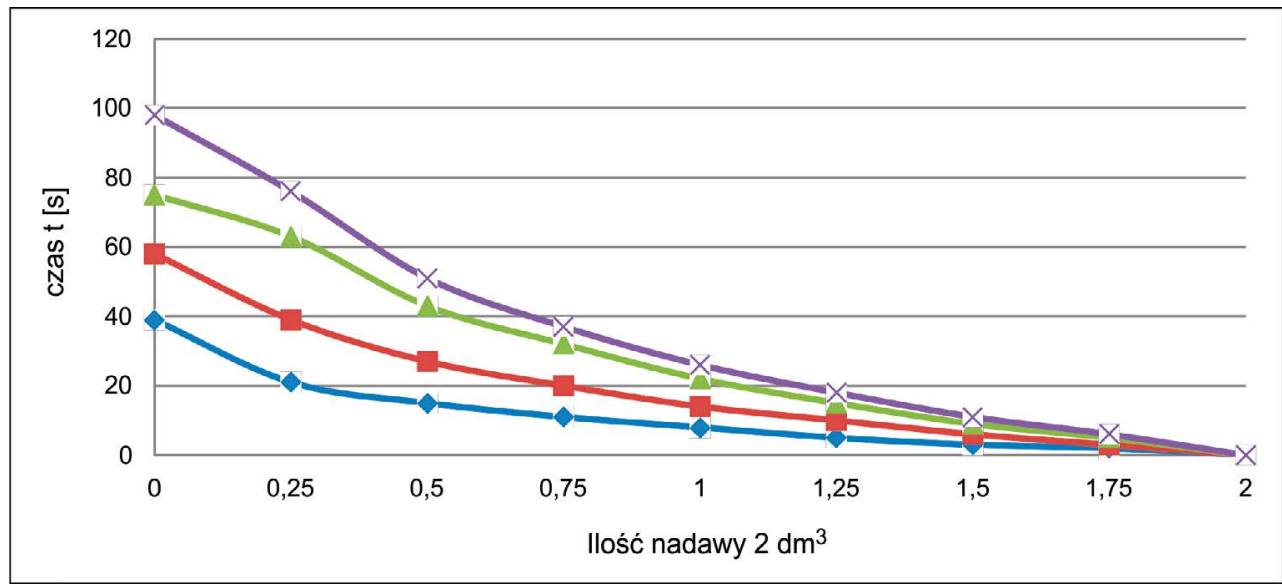

Rys. 10. Przepływ nadawy o zagęszczeniu $\beta=10,20,30,40 \mathrm{~g} / \mathrm{dm}^{3}$ w $2 \mathrm{dm}^{3}$

Fig. 10. The flow of feed on density $\beta=10,20,30,40 \mathrm{~g} / \mathrm{dm}^{3}$ in $2 \mathrm{dm}^{3}$

Po przeanalizowaniu otrzymanych wyników zestawionych $\mathrm{w}$ tabelach sporządzono wykresy dotyczące filtracji grawitacyjnej dla różnych parametrów, takich jak zagęszczenie nadawy węglem w stosunku zagęszczenia $\beta=10 \mathrm{~g} / \mathrm{dm}^{3}, 20 \mathrm{~g} / \mathrm{dm}^{3}, 30 \mathrm{~g} / \mathrm{dm}^{3}, 40 \mathrm{~g} / \mathrm{dm}^{3}$ oraz różne przepływy mieszaniny wody przez siatkę filtracyjną odpowiednio dla $1 \mathrm{dm}^{3} ; 1,5 \mathrm{dm}^{3}$ oraz $2 \mathrm{dm}^{3}$ nadawy. 
Tabela 13. Zestawienie czasu przepływu nadawy dla zagęszczenia $\beta=10,20,30,40 \mathrm{~g} / \mathrm{dm}^{3} \mathrm{dla}_{2} \mathrm{dm}^{3}$

Table 13. Summary of the feed flow time for compaction $\beta=10,20,30,40 \mathrm{~g} / \mathrm{dm}^{3}$ for $2 \mathrm{dm}^{3}$

\begin{tabular}{|c|c|r|r|r|r|}
\hline Lp. & Ilość nadawy $\left[\mathrm{dm}^{3}\right]$ & \multicolumn{4}{|c|}{ Czas $\mathrm{t}[\mathrm{s}]$} \\
\hline 1. & 2,00 & 0,00 & 0,00 & 0,00 & 0,00 \\
\hline 2. & 1,75 & 2 & 3 & 5 & 6 \\
\hline 3. & 1,50 & 3 & 6 & 9 & 11 \\
\hline 4. & 1,25 & 5 & 10 & 15 & 18 \\
\hline 5. & 1,00 & 8 & 14 & 22 & 26 \\
\hline 6. & 0,75 & 11 & 20 & 32 & 37 \\
\hline 7. & 0,50 & 15 & 27 & 43 & 51 \\
\hline 8. & 0,25 & 39 & 39 & 63 & 76 \\
\hline 9. & 0,00 & & & 75 & 98 \\
\hline
\end{tabular}

Przykładowo, z danych na rysunku 4, który przedstawia zależność stałej filtracji $b$ od zagęszczenia nadawy, można wnioskować, że wraz ze wzrostem zagęszczenia cieczy rośnie wartość stałego współczynnika filtracji $b$. Z kolei na wykresie (rys. 5), który dotyczy wpływu zagęszczenia nadawy $\beta$ na czas filtracji dla objętości nadawy można zauważyć, że wraz ze zwiększeniem zagęszczenia nadawy proces filtracji grawitacyjnej przebiegał wolniej. I tak dla zagęszczenia $\beta=10 \mathrm{~g} / \mathrm{dm}^{3}$ czas filtracji grawitacyjnej wyniósł $20 \mathrm{~s}$, dla $\beta=20 \mathrm{~g} / \mathrm{dm}^{3}$ czas filtracji wyniósł $29 \mathrm{~s}$. Dla największego badanego zagęszczenia $\beta=40 \mathrm{~g} / \mathrm{dm}^{3}$ czas filtracji wyniósł $62 \mathrm{~s}$.

Wykresy na kolejnych rysunkach przedstawiają przepływ nadawy z różnymi zagęszczeniami $\beta$ dla odpowiednich upływów czasowych.

Na podstawie przedstawionych danych (rys. 5-10) można zauważyć, że prędkość filtracji na początku była duża, a z czasem zmniejszała się. Na siatce tworzył się stopniowo placek filtracyjny, co zwiększało opór przepływu i tym należy tłumaczyć mechanizm przyczynowo-skutkowy zmniejszania się prędkości filtracji wraz z czasem jej trwania.

\section{Wnioski}

W wyniku przeprowadzonych badań o charakterze podstawowym, dotyczących procesu filtracji grawitacyjnej mieszanin (zawiesin) węglowych, można podać następujące ogólne wnioski:

1. Określona na podstawie ogólnego równania Darcy stała siatki filtracyjnej $t^{\prime}$ ustalona dla procesu przepływu cieczy przez tę siatkę, zależała od objętości nadanej cieczy, co w przeliczeniu dawało napór średni od 2050 do około $4050 \mathrm{~N} / \mathrm{m}^{2}$ - wahała się w granicach od 182830 714,3 do 228220 909,1 1/m. Wartości te należy uznać za bardzo duże. 
2. Wartość stałej $b \mathrm{w}$ ogólnym równaniu (7) według Piecucha dla różnych wartości zagęszczenia nadawy; $\beta=10 \mathrm{~g} / \mathrm{dm}^{3}, \beta=20 \mathrm{~g} / \mathrm{dm}^{3}, \beta=30 \mathrm{~g} / \mathrm{dm}^{3}, \beta=40 \mathrm{~g} / \mathrm{dm}^{3}-$ zmieniała się następująco:

- dla objętości nadawy $1 \mathrm{dm}^{3} \mathrm{w}$ granicach od $8,97 \cdot 10^{-9}$ do $1,35 \cdot 10^{8}$,

- dla objętości nadawy $1 \mathrm{dm}^{3} \mathrm{w}$ granicach od $1,33 \cdot 10^{-8}$ do $2,25 \cdot 10^{-8}$,

- dla objętości nadawy $1 \mathrm{dm}^{3} \mathrm{w}$ granicach od $1,80 \cdot 10^{-8}$ do $2,98 \cdot 10^{-8}$,

a więc są to liczby wielocyfrowe o bardzo małych wartościach ułamkowych.

\section{Symbolika oznaczeń}

$a-$ powierzchnia filtracji $\left[\mathrm{m}^{2}\right]$,

$b$ - stała w równaniu oporu osadu i w ogólnym równaniu filtracji [-],

$L$ - grubość przegrody porowatej [m],

$L_{s}-$ grubość siatki filtracyjnej [m],

$L_{z l}-$ grubość złoża filtracyjnego na siatce filtracyjnej [m],

$L_{O}-$ grubość osadu [m],

$\Delta p-$ ciśnienie filtracji $\left[\mathrm{N} / \mathrm{m}^{2}\right]$,

$R_{S}-$ całkowity opór siatki $\left[\mathrm{N} \cdot \mathrm{s} / \mathrm{m}^{5}\right]$,

$R_{z l}-$ całkowity opór złoża filtracyjnego $\left[\mathrm{N} \cdot \mathrm{s} / \mathrm{m}^{5}\right]$,

$R_{o s}-$ całkowity opór osadu $\left[\mathrm{N} \cdot \mathrm{s} / \mathrm{m}^{5}\right]$,

$t^{\prime}-$ stała siatki filtracyjnej $[1 / \mathrm{m}]$,

$u$ - prędkość filtracji $[\mathrm{m} / \mathrm{s}]$,

$\dot{V}-$ wydajność objętościowa $\left[\mathrm{m}^{3} / \mathrm{s}\right]$,

$\beta_{n}-$ zagęszczenie nadawy $\left[\mathrm{g} / \mathrm{dm}^{3}\right]$,

$\mu-$ lepkość dynamiczna $\left[\mathrm{N} \cdot \mathrm{s} / \mathrm{m}^{2}\right]$,

$\delta_{s}-$ ciężar właściwy stałych zanieczyszczeń w nadanej mieszaninie $\left[\mathrm{N} / \mathrm{m}^{3}\right]$,

$\varepsilon-$ porowatość $[-]$.

\section{LITERATURA}

Anielak, A.M. 2000. Chemiczne i fizykochemiczne oczyszczanie ścieków. PWN, Warszawa

Dahlstrom, D.A. 1954. Theory and practice of filtration. Międzynarodowy Kongres Przeróbki Mechanicznej. Essen. Gumińska, J. 2007. The influence of microfloc age on its strength and sorption capactty. Environmental Protection Engineering No 1, p. 5-14

Hewelke i in. 2014 - Hewelke, E., Szatyłowicz, J., Gnatowski, T. i Oleszczuk, R. 2014. Zmienność przestrzenna uwilgotnienia hydrofobowej gleby organicznej w warunkach przepływu preferencyjnego. Rocznik Ochrona Środowiska t. 16, s. 580-607 (Annual Set the Environment Protection vol. 16, p. 580-607).

Kabsch-Korbutowicz, M. i Urbanowska, A. 2009. Proces MIEX®DOC jako metoda przydatna do wstępnego oczyszczania wody przed procesem filtracji na membranach ceramicznych. Rocznik Ochrona Środowiska t. 11, s. 595-606 (Annual Set the Environment Protection vol. 11, p. 595-606). 
Kliber, S. i Wiśniewski, J.A. 2009. Membranowy proces wymiany anionów jako metoda zmiany składu jonowego wody. Rocznik Ochrona Środowiska t. 11, s. 985-994 (Annual Set the Environment Protection vol. 11, p. 985-994)

Ostrowska i in. 2013 - Ostrowska, K., Janczukowicz, W., Radziewicz, J. i Mielcarek, A. 2013. Wpływ procesu filtracji na relacje między ilością substancji organicznych i związków biogennych w ściekach mleczarskich. Rocznik Ochrona Środowiska t. 15, s. 1411-1425 (Annual Set the Environment Protection vol. 15, p. 1411-1425).

Piecuch. T, 2009. Równanie Darcy jako podstawa analizy teoretycznej szczególnych przypadków procesu filtracji. Rocznik Ochrona Środowiska t. 11, cz. 1, s. 299-320 (Annual Set the Environment Protection vol. 11, p. 299-320)

Piecuch, T., 2010. Technika wodno-mułowa, urządzenia i procesy. W.N.T., Warszawa.

Piekarski, J. 2011. Zastosowanie metod numerycznych do modelowania procesu filtracji grawitacyjnej. Rocznik Ochrona Środowiska t. 13 , Rok 2011, s. 315-332 (Annual Set the Environment Protection vol. 13, p. 315-332).

Tomaszewska, B. 2011. The Use of Ultrafiltration and Reverse Osmosis in the Desalination of Low Mineralized Geothermal Waters. Archives of Environmental Protection vol. 37, No 3.

WYZNACZENIE STAŁYCH WSPÓŁCZYNNIKÓW

W RÓWNANIU OGÓLNYM FILTR ACJI GRAWITACYJNEJ ZAWIESIN WEGLOWYCH

\author{
Słowa kluczowe
}

filtracja, filtracja grawitacyjna, stałe współczynniki, węgiel kamienny

\title{
Streszczenie
}

W powyższej publikacji, opisując badania o charakterze podstawowym, zaprezentowano jeden ze sposobów wyznaczenia stałych współczynników w filtracji grawitacyjnej, występujących w ogólnym równaniu filtracji (Piecuch 2009, 2010).

Wykonano badania laboratoryjne dotyczące filtracji grawitacyjnej, stosując jako zmienne: objętość nadawy $\left(1 \mathrm{dm}^{3} ; 1,5 \mathrm{dm}^{3} ; 2 \mathrm{dm}^{3}\right)$, stopień jej zagęszczenia $\left(10 \mathrm{~g} / \mathrm{dm}^{3}, 20 \mathrm{~g} / \mathrm{dm}^{3}, 30 \mathrm{~g} / \mathrm{dm}^{3}, 40 \mathrm{~g} / \mathrm{dm}^{3}\right)$ oraz napór średni słupa cieczy. Jako zanieczyszczenie nadawy użyto węgla kamiennego o klasie ziarnowej zawartej w granicach od 0,315 do $0,5 \mathrm{~mm}$, która była większa od średnicy oczek na siatce filtracyjnej. Przy tak modelowanym doświadczeniu zagęszczenie filtratu było równe zero. Jest to ważne dla przeniesienia badań o charakterze podstawowym na badania o charakterze aplikacyjnym.

Na podstawie otrzymanych wyników sporządzono ich graficzne oraz tabelaryczne zestawienie. W pierwszej serii badań oraz obliczeń określono wartość stałej siatki filtracyjnej $t^{\prime}$, która rosła wraz ze wzrostem ciśnienia filtracji. W drugiej serii badań oraz obliczeń określono wartość stałego współczynnika $b$, występującego w równaniu oporu osadu i w ogólnym równaniu filtracji (Piecuch 2009, 2010).

Stwierdzono, że wraz ze wzrostem zagęszczenia nadawy, wzrasta wartości stałego współczynnika filtracji grawitacyjnej określanego symbolem $b$, natomiast proces filtracji grawitacyjnej przebiega wolniej. Zwrócono uwagę, że dla przyjętego w obliczeniach układu jednostek SI, wartości obydwu wyznaczonych współczynników $t^{\prime}$ oraz $b$ stanowią liczby wielocyfrowe o wartościach bardzo dużych $\left(t^{\prime}\right)$ oraz bardzo małych ułamków $(b)$. W tym odniesieniu obliczenia nie są łatwe. 


\section{CONSTANT COEFFICIENTS BEING TAKEN \\ IN THE GENERAL EQUATION GRAVITY FILTRATION OF COAL SLURRIES}

Key words

filtration, gravity filtration, constant coefficients, hard coal

Abstract

In the above publication describing the research of a fundamental nature presents one of the methods for determining the constant coefficients a gravity filtration. occurring in the general equation filtration (Piecuch 2009, 2010). The laboratory tests concerning the gravitational filtration were performed, applying variables: capacity of the feed $\left(1 \mathrm{dm}^{3}, 1.5 \mathrm{dm}^{3}, 2 \mathrm{dm}^{3}\right)$, a degree of density $\left(10 \mathrm{~g} / \mathrm{dm}^{3}, 20 \mathrm{~g} / \mathrm{dm}^{3}, 30 \mathrm{~g} / \mathrm{dm}^{3}, 40 \mathrm{~g} / \mathrm{dm}^{3}\right)$ and medium pressure of the column of liquid. As polluting the feed they used the hard bituminous coal about the determined faction entered into within the limits of by $0.315 \mathrm{~mm}$ up to $0.5 \mathrm{~mm}$ which was larger than the diameter of eyes on the mesh filter. With such experience modeled density of the filtrate was zero. This is important for the transfer of a basic research on studies of an application.

Based on received results prepared graphical and tabular statement. The first series of tests and calculations is set to a constant mesh filter $t^{\prime}$, which has risen with the increase in pressure filtration. In the second series of tests and calculations is set to a constant coefficient $b$ in the equation of resistance occurring sediment and the general equation of filtration (Piecuch 2009, 2010).

They stated, that along with the height of thickening the feed, a value of the constant coefficient of the gravity filtration is growing determined with $b$ symbol, however the process of the gravity filtration is proceeding more slowly. It was noted that for assumed in the calculations SI, the value of both set of coefficients $t^{\prime}$ and $b$ represent the number of multi- valued very large $\left(t^{\prime}\right)$ and a very small fraction $(b)$. In this regard calculation is not easy. 
